Revue d'histoire de l'Amérique française

MAV REVUE D.HISTOIRE DE L'AMÉRIQUE FRANÇAISE

\title{
Texte d'introduction au dossier « L’Atlantique français et ses frontières : résistances, circulations, savoirs »
}

\section{Jean-Pierre Le Glaunec, Carolyn Fick et François Furstenberg}

Volume 71, numéro 1-2, été-automne 2017

L’Atlantique français et ses frontières : résistances, circulations, savoirs

URI : https://id.erudit.org/iderudit/1042784ar

DOI : https://doi.org/10.7202/1042784ar

Aller au sommaire du numéro

\section{Éditeur(s)}

Institut d'histoire de l'Amérique française

\section{ISSN}

0035-2357 (imprimé)

1492-1383 (numérique)

Découvrir la revue

Citer ce document

Le Glaunec, J.-P., Fick, C. \& Furstenberg, F. (2017). Texte d'introduction au dossier "L'Atlantique français et ses frontières : résistances, circulations, savoirs ". Revue d'histoire de l'Amérique française, 71(1-2), 9-11.

https://doi.org/10.7202/1042784ar d'utilisation que vous pouvez consulter en ligne. 


\title{
Texte d'introduction au dossier
“L'Atlantique français
et ses frontières :
résistances, circulations, savoirs ” \\ Jean-Pierre Le Glaunec \\ Université de Sherbrooke \\ CAROLYN Fick \\ Université Concordia \\ FrançOIS FurSTENBERG \\ Université Johns Hopkins
}

\begin{abstract}
$\grave{A}$
'origine de ce dossier est l'atelier "Les résistances à l'esclavage dans le monde atlantique français à l'ère des Révolutions - 1750-1850" organisé par le Groupe d'histoire de l'Atlantique français en collaboration avec le Haiti Lab (Duke University) et le Centre international de recherches sur les esclavages (CNRS). Tenu à Montréal en 2013, l'atelier réunissait une quinzaine de chercheurs venant d'Amérique du Nord, d'Angleterre et de France, tous reconnus pour leur expertise dans le champ des résistances à l'esclavage dans l'Atlantique français et l'océan Indien, aux $\mathrm{XVIII}^{e}$ et XIX ${ }^{e}$ siècles. L'objectif premier était de faire le point sur une historiographie souvent mal connue à l'extérieur du monde des spécialistes francophones, d'en situer l'évolution et de comprendre les raisons de son développement relativement limité comparé aux travaux portant, notamment, sur les sociétés esclavagistes anglophones.

On cherchait à savoir comment et avec quels motifs les esclaves résistaient dans le monde atlantique français entre le milieu des années 1750 et l'abolition définitive de l'esclavage en 1848? Comment les autorités cherchaient-elles à contrôler et à endiguer leurs actes de résistance, à quadriller et à surveiller les espaces marginaux, ruraux et urbains, de leur
\end{abstract}


société respective? Quel impact avaient les diverses formes de marronnage (nom donné à la fuite d'un esclave) à l'ère des Révolutions? Quels types de solidarités (ethnique, de genre, de classe, etc.) les hommes et femmes esclavisés déployaient-ils pour faire entendre leur voix ou pour contester un aspect de leur existence? Quel rôle avaient des résistances culturelles comme la danse, la musique, les pratiques vestimentaires ou encore les performances corporelles? La variété des questions abordées par les participants reflétait la multiplicité des situations possibles, influencées par des facteurs de nature diverse, internes ou externes, comme l'intensité des migrations d'esclaves, la topographie, les conflits impériaux, les ratios hommes/femmes, Créoles/Africains, et tant d'autres. Un autre aspect important de l'atelier portait sur le rôle que les humanités numériques ont - et pourraient avoir - dans le renouvellement des questionnements et des pratiques des historiens du monde atlantique français dans l'écriture des résistances d'esclaves.

De cet atelier est né le présent dossier, qui met en dialogue trois auteurs: Jean-Pierre Le Glaunec, Sue Peabody et François Dominic Larramée.

Jean-Pierre Le Glaunec montre, dans un premier temps, que l'objet «résistance à l'esclavage» n'occupe pas la juste place qui lui revient dans l'historiographie française. Alors que la question n'a pas cessé d'être étudiée dans l'historiographie anglo-saxonne depuis les années 1960 (malgré les appels récents de certains historiens à plus de nuance, étant donné le rapport de force inégal inhérent à toute société esclavagiste), l'auteur est frappé par la rareté (et la marginalité) des travaux en France et par la perspective typologique généralement adoptée pour en parler, comme si les esclaves « résistants» devaient se contenter de rôles de figurants et leurs actions se réduire à des catégories à classer. L'auteur propose certaines pistes d'explication pour rendre compte de ce phénomène historiographique, parmi lesquelles sont le contraste entre le contexte politique et social en France dans les années 1960 et celui qui voit l'émergence des études noires aux États-Unis et la mise en place d'une historiographie de la résistance à l'esclavage ; l'émergence de l'autonomisme et de l'indépendantisme dans les Antilles françaises et la Réunion; la marginalisation géographique et institutionnelle des auteur-e-s; ou encore la place prépondérante dans l'historiographie du marronnage (en Haïti par exemple) au détriment d'autres formes de résistance peut-être moins visibles et spectaculaires. Il fait état, en conclusion, d'un tournant récent (datant des années 1990) porté par des chercheur-e-s dont l'objectif est de faire toute la lumière sur l'agentivité des hommes et femmes esclavisés du monde atlantique français. 
Sue Peabody fait partie de ce tournant. Dans son article, elle s'intéresse aux poursuites judiciaires intentées par des esclaves en vue de s'affranchir, et ébauche, par son utilisation des sources judiciaires, une autre manière de faire l'histoire sociale de l'esclavage. L'article s'appuie sur une poursuite en particulier, celle de l'esclave Furcy, de l'île Bourbon (la Réunion), mais la situe dans un contexte transnational qui fait le lien entre les Antilles, l'océan Indien et les États-Unis. La question en jeu est le principe du «sol libre", selon lequel les esclaves qui circulent par-delà certaines frontières deviennent libres. Se trouvant à l'île Maurice, territoire britannique, au moment de l'application de l'Acte d'émancipation britannique en 1835, Furcy est un homme libre mais ne peut faire valoir sa liberté devant la justice française (aux prises avec la politique régressive sur l'esclavage de la Monarchie de Juillet) qu'à la veille de l'émancipation générale en 1848. Au final, l'auteure montre comment, malgré la portée limitée du principe $\mathrm{du}$ «sol libre» dans les cas d'affranchissement individuels, l'affaire Furcy a pu servir de vecteur pour alimenter le discours abolitionniste dans les années 1840 dans les espaces publics, judiciaires et gouvernementaux, contribuant ainsi à l'objectif ultime de mettre fin à l'esclavage.

Si François Dominic Laramée n'aborde qu'indirectement la problématique de la résistance dans sa contribution, il la contextualise en proposant un survol de l'historiographie récente sur le monde atlantique français. Approche bien implantée dans l'historiographie anglophone de la période moderne pour étudier les interactions entre les Amériques, l'Europe et l'Afrique, la perspective "atlantique» est moins un pôle de discussion pour les chercheurs francophones en Europe et au Québec - même si, comme le démontre Laramée, cette perspective est loin d'être absente. Pour bien situer la contribution que les travaux sur l'espace francophone peuvent apporter au champ atlantique dans son ensemble, Laramée se concentre sur trois cas d'étude: la contrebande comme élément clé d’une économie plus intégrée et poreuse que pourraient le laisser entendre des travaux à l'échelle strictement nationale; les résistances variées à l'esclavage à travers les espaces du monde atlantique français; et la circulation des savoirs et les tensions entre les échanges étatiques ou paraétatiques et la réalité coloniale. Le texte de Laramée suggère qu'une approche atlantique peut remettre en cause les récits les plus fondamentaux de la modernité ellemême. Une modernité complexe et non stable, hétérogène et non homogène, marquée par une circulation des savoirs à travers lesquels se lisent les tensions du monde atlantique: entre secret et ouverture, contingence et «machine coloniale», facteurs spécifiques et locaux et État impérial. 